\title{
Reliability of the Pinch Strength with Digitalized Pinch Dynamometer
}

\author{
Heesuk Shin, M.D., Ph.D., Seung Won Moon, M.D., Gab-Soon Kim, Ph.D. ', Jung Dong Park, M.D., \\ Jin Hoan Kim, M.D., Mi Jin Jung, M.D., Chul Ho Yoon, M.D., Eun Shin Lee, M.D., Min-Kyun Oh, M.D. \\ Department of Rehabilitation Medicine, Gyeongsang National University Hospital, \\ ${ }^{1}$ Control and Instrumentation Engineering, ERI, Gyeongsang National University, Jinju 660-702, Korea
}

Objective To examine the intra-rater, inter-rater, and inter-instrumental reliability of the digitalized pinch muscle strength dynamometer.

Method Thirty normal subjects were examined for pinch strength, using both the Preston pinch gauge and the digitalized pinch dynamometer. The participants performed all pinch strength tests in the seated position as recommended by the American Society of Hand Therapists (ASHT). Three successive measurements were taken for each hand. The mean of the three trials was used for data analysis. The pinch strength tests performed used a repeated measure design and measurements were taken by each rater.

Results The relationship between the Preston pinch gauge and the digitalized pinch dynamometer in pinch strength was reliable (the ICC were 0.821 and 0.785 in rater 1 and rater 2 respectively). The relationship between the first session and second session in pinch strength using the digitalized pinch dynamometer was reliable (the ICC were 0.872 and 0.886 in rater A and rater B respectively). The relationship between rater A and rater B in pinch strength using the digitalized pinch dynamometer was reliable (the ICC was 0.754 ).

Conclusion The pinch strength measurement using the digitalized pinch dynamometer is reliable within the rater and between raters. Thus, the Preston pinch gauge and the digitalized dynamometer measure grip strength equivalently, and can be used interchangeably.

Key Words Pinch strength, Muscle strength dynamometer, Reliability

Received January 31, 2012; Accepted March 26, 2012

Corresponding author: Chul Ho Yoon

Department of Rehabilitation Medicine, Gyeongsang National University Hospital, 90, Chilamdong, Jin-ju 660-702, Korea

Tel: +82-55-750-8252, Fax: +82-55-750-8255, E-mail: yoonch@gnu.ac.kr (c) This is an open-access article distributed under the terms of the Creative Commons Attribution Non-Commercial License (http:// creativecommons.org/licenses/by-nc/3.0) which permits unrestricted noncommercial use, distribution, and reproduction in any medium, provided the original work is properly cited.

Copyright () 2012 by Korean Academy of Rehabilitation Medicine

\section{INTRODUCTION}

Hand strength has been widely used in clinical practice as an objective index for functionality of the upper limbs. ${ }^{1,2}$ It is very important to measure hand strength accurately because it can serve as an indicator of the progress of treatment and rehabilitation of the damaged hand. ${ }^{3}$ The importance of measuring hand strength has been emphasized in the past: in 1985, Mathiowetz et al. ${ }^{4}$ stated that normative data of hand strength are required for the assessment of patients, to set a practical treatment 
goal and to make a vocational evaluation in order for patients to return to work.

Hand strength can be obtained by measuring several kinds of pinch strength such as grip strength, tip strength, key pinch strength and tripod pinch strength. ${ }^{3}$ The Jamar grip dynamometer and Jamar pinch gauge are the most widely used instruments for measuring grip and pinch strength. ${ }^{5,6}$ Since first introduced by Bechtol ${ }^{7}$ in 1954, the Jamar grip dynamometer has shown high interinstrumental and inter-rater reliability in many studies. ${ }^{8}$ Also, it has standard values for adults and children which can easily be used clinically. ${ }^{9}$ However, the Jamar grip dynamometer requires frequent calibration to maintain its reliability, and reading with an analogue scale may result in measurement error. ${ }^{10}$

During the past 20 years, a number of digitalized dynamometers have been used in clinical practice. But the existing normative values for grip strength were taken by the Jamar grip dynamometer, so they have many restrictions in comparison with the values from digitalized measuring instruments. To this end, studies on the reliability between the digital dynamometers, like DynEx ${ }^{11}$ and Computerized Jamar Dynamometer, ${ }^{12}$ and between these instruments and the Jamar grip dynamometer,

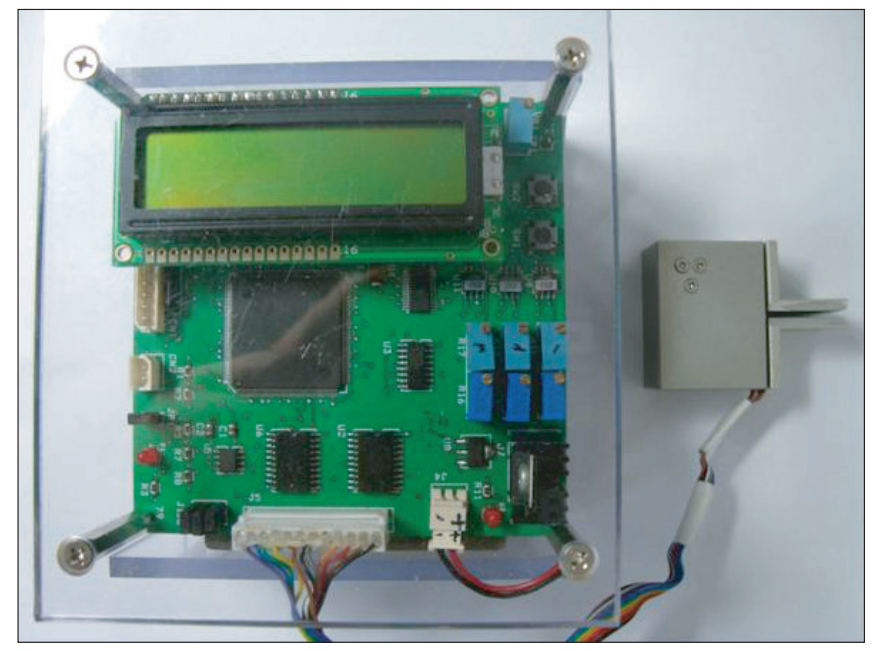

Fig. 1. Digitalized Pinch Dynamometer. which is the standard instrument, have been carried out.

In contrast to the international case, the domestic development of digitalized measuring instruments is a relatively new phenomenon resulting in the analogue Jamar dynamometer still being used clinically in South Korea. The purpose of this study is to verify whether the Digitalized Pinch Dynamometer (Fig. 1) developed at our institute can be used clinically; this was done by conducting tests of inter-test and inter-rater reliability in measuring key pinch, and by comparing the results of this dynamometer with those of the hydraulic Preston pinch gauge (Sammons Preston, Illinois, USA), which is now being used in our Occupational Therapy Center.

\section{MATERIALS AND METHODS}

\section{Subjects}

Subjects consisted of 30 healthy adults ( 23 males, 7 females) aged 23-33 years. They had an average age of 27.8 years (male: 28.1, female: 27.7), average height of 173.5 cm (male: $176.4 \pm 5.7$, female: $168.8 \pm 7.4$ ) and average weight of $68.6 \mathrm{~kg}$ (male: $74.3 \pm 7.3$, female: $61.2 \pm 13.7$ ). 23 of the subjects were right-handed $(76.7 \%)$ and 7 were lefthanded (23.3\%).

All subjects had no lesion or history of lesion of the nervous, muscular and skeletal system which might affect their hand functionality. Those who had injury or pain at the time of the test were excluded (Table 1).

\section{Digitalized Pinch Dynamometer}

The Digitalized Pinch Dynamometer is a measuring instrument designed and developed by our Control and Measurement Engineering Department. It consists of a high-speed gauge and a two-fingered power measurement device. The two-fingered power measurement device uses the 3-axis power sensor method that allows precise measurement at 10-gram intervals. It measures the pressing power of two fingers and sends the measured values to a high-speed gauge to calculate the force, which is displayed on the LCD and transmitted to the computer

Table 1. Physical Characteristics of Subjects

\begin{tabular}{lccccc}
\hline \multicolumn{1}{c}{ Sex } & Number & Age (years) & Weight (kg) & Height (cm) & $\begin{array}{c}\text { Dominant hand } \\
\text { (right : left) }\end{array}$ \\
\hline Male & 23 & $28.13 \pm 3.15$ & $74.3 \pm 7.29$ & $176.43 \pm 5.74$ & $18: 5$ \\
Female & 7 & $27.71 \pm 2.72$ & $61.21 \pm 13.68$ & $168.78 \pm 7.43$ & $5: 2$ \\
\hline
\end{tabular}


simultaneously. The measured values are transmitted to the computer every 0.8 second and these measurements are converted into a force graph which is displayed on the computer screen (Fig. 2). ${ }^{13}$

\section{Methods}

We used the Preston Pinch Gauge (Fig. 3) and Digitalized Pinch Dynamometer to measure pinch strength. Measurement was achieved by pressing the front part of the thumb together with the side part of the index finger (Fig. 4) in the standard position proposed by the American Society of Hand Therapists. ${ }^{14,15}$ In this position, subjects were seated in a chair, with their shoulders adducted and neutrally rotated, their elbows flexed 90 degrees, their forearms positioned neutrally, and their wrists

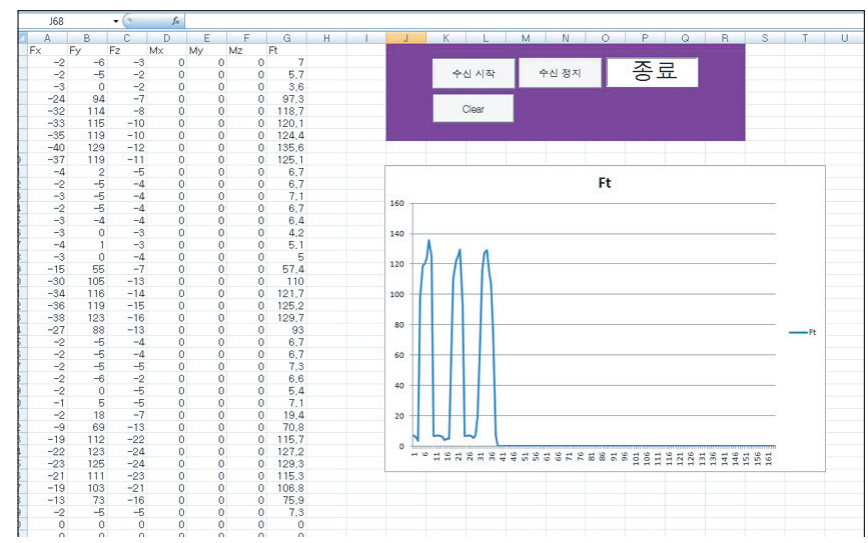

Fig. 2. Display window for the Digitalized Pinch Dynamometer.

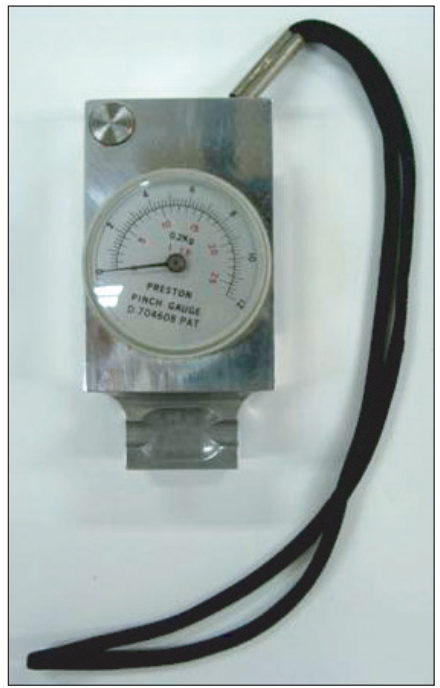

Fig. 3. Preston Pinch Gauge. flexed in 0-30 degrees and 0-15 degrees of ulnar deviation (Fig. 5). At first, rater 1 informed the subjects about the measurement procedure and gave them a verbal command to exert their maximum strength for 3 to 5 seconds. Mean values were recorded after measuring three consecutive tests with both their hands. According to those procedures, pinch strengths of the subjects' left and right hand were measured with the Preston Pinch Gauge, and then with the Digitalized Pinch Dynamometer after a 10-minute break. After this, pinch strength was measured

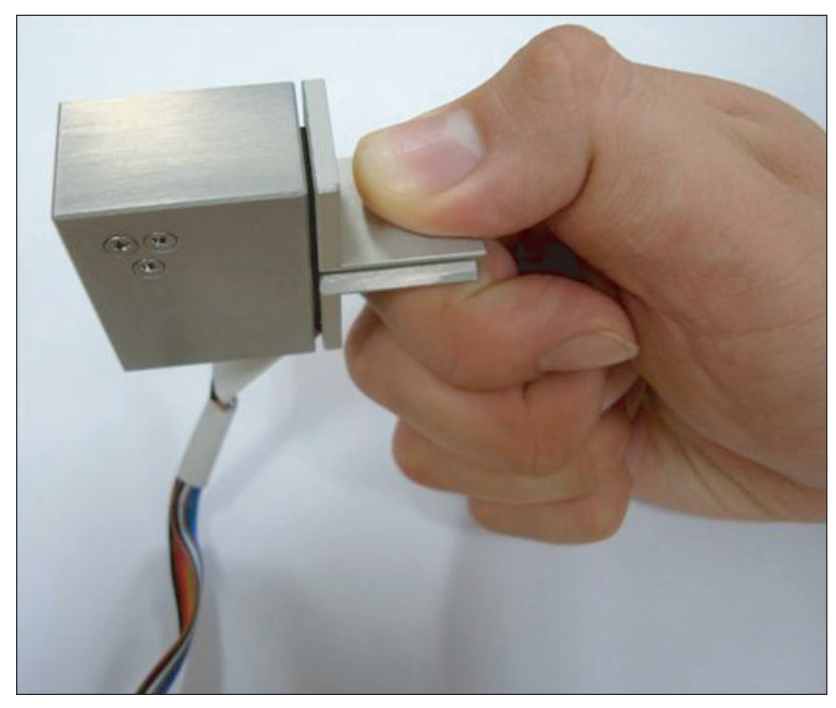

Fig. 4. The key pinch power was checked between the pulp of the thumb and the radial aspect of the middle phalanx of the index finger.

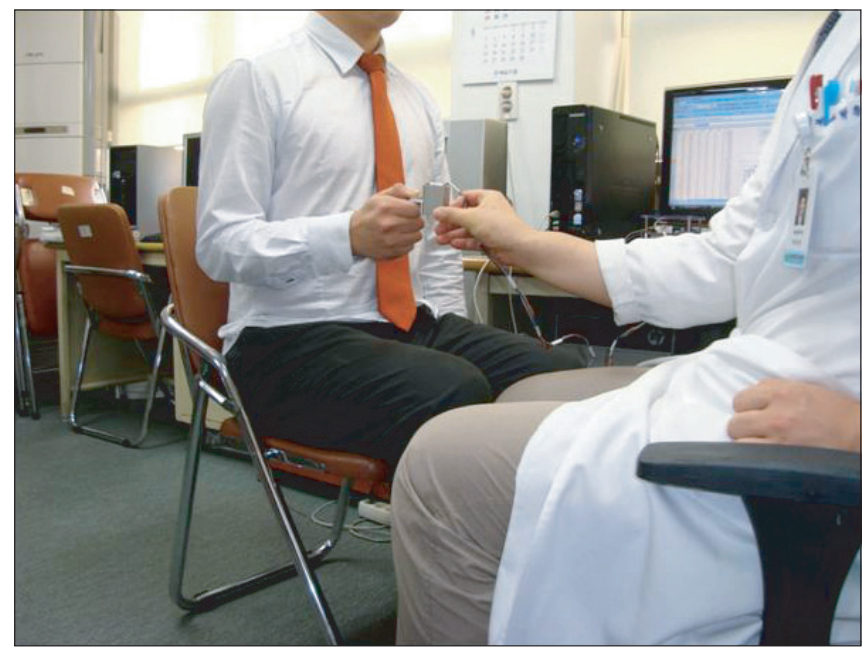

Fig. 5. Pinch strength was evaluated with shoulder adduction, elbow in 90 degree flexion and neutrally rotated forearm. 
again with the Digitalized Pinch Dynamometer after 10 minutes in order to evaluate the inter-instrumental reliability of the dynamometer. Rater 2 conducted the measurement in the same way one hour after the testing by rater 1 was concluded. The results of measurement of the two raters were kept hidden from the other rater.

\section{Statistics}

We used statistical analysis tool SPSS version 17.0, and performed a paired T-test to check the difference of the measured values between the Preston Pinch Gauge and Digitalized Pinch Dynamometer. Intraclass correlation coefficient (ICC) was used to evaluate inter-instrumental and intra-rater reliability of the measurement. In this study, it was considered statistically significant when the p-value was 0.05 or less.

\section{RESULTS}

Pinch strength measured with Preston Pinch Gauge and Digitalized Pinch Dynamometer

The mean values of measurement with the Preston Pinch Gauge were: $9.65 \pm 1.21 \mathrm{~kg}$ (right), $8.87 \pm 1.51 \mathrm{~kg}$ (left) for males, and $6.22 \pm 1.03 \mathrm{~kg}$ (right), $5.98 \pm 1.62 \mathrm{~kg}$ (left) for females (Table 2). The mean values of measurement

Table 2. Mean and Standard Deviation Values of Pinch Strength by Preston Pinch Gauge

\begin{tabular}{ccc}
\hline \multicolumn{1}{c}{ Sex } & Right (kg) & Left (kg) \\
\hline Male & $9.65 \pm 1.21$ & $8.87 \pm 1.51$ \\
Female & $6.22 \pm 1.03$ & $5.98 \pm 1.62$ \\
\hline
\end{tabular}

with Digitalized Pinch Dynamometer conducted by rater 1 were: on the first test, $9.58 \pm 1.12 \mathrm{~kg}$ (right), $8.91 \pm 1.53$ $\mathrm{kg}$ (left) for males, and $6.17 \pm 0.94 \mathrm{~kg}$ (right), $6.17 \pm 1.64$

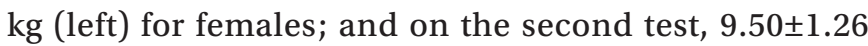
$\mathrm{kg}$ (right), $8.69 \pm 1.56 \mathrm{~kg}$ (left) for males, and $6.48 \pm 1.05 \mathrm{~kg}$ (right), $5.92 \pm 1.41 \mathrm{~kg}$ (left) for females. The mean values of measurement conducted by rater 2 were: on the first test, $9.22 \pm 1.68 \mathrm{~kg}$ (right), $8.31 \pm 1.67 \mathrm{~kg}$ (left) for males, and $6.18 \pm 1.11 \mathrm{~kg}$ (right), $5.80 \pm 1.26 \mathrm{~kg}$ (left) for females; and on the second test; $9.07 \pm 1.62 \mathrm{~kg}$ (right), $8.48 \pm 1.79 \mathrm{~kg}$ (left) for males, and $5.90 \pm 1.33 \mathrm{~kg}$ (right), $5.44 \pm 1.15 \mathrm{~kg}$ (left) for females (Table 3).

The difference between the mean values of pinch strength measured with the Preston Pinch Gauge and Digitalized Pinch Dynamometer was not statistically significant when measured by rater 1 , but was significant when measured by rater 2 (Table 4 ).

\section{Inter-instrumental reliability of Preston Pinch Gauge} and Digitalized Pinch Dynamometer

Correlation coefficients between the pinch strength values measured with the Preston Pinch Gauge and the values measured by each rater with the Digitalized Pinch Dynamometer were 0.82 for rater 1 , and 0.78 for rater 2 . All the correlation coefficients were statistically significant (Table 5) $(\mathrm{p}<0.001)$.

\section{Comparison between the first and the second test of Digitalized Pinch Dynamometer}

Correlation coefficients between the pinch strength values measured from the first test and the second test were 0.87 when done by rater 1 , and 0.88 by rater 2 . All the cor-

Table 3. Mean and Standard Deviation Values of Pinch Strength by Digitalized Pinch Dynamometer

\begin{tabular}{|c|c|c|c|c|c|}
\hline \multirow{2}{*}{ Sex } & \multirow{2}{*}{ Session } & \multicolumn{2}{|c|}{ Rater 1} & \multicolumn{2}{|c|}{ Rater 2} \\
\hline & & Right (kg) & Left (kg) & Right (kg) & Left (kg) \\
\hline \multirow[t]{2}{*}{ Male } & 1 st & $9.58 \pm 1.12$ & $8.91 \pm 1.53$ & $9.22 \pm 1.68$ & $8.31 \pm 1.67$ \\
\hline & 2nd & $9.50 \pm 1.26$ & $8.69 \pm 1.56$ & $9.07 \pm 1.62$ & $8.48 \pm 1.79$ \\
\hline \multirow[t]{2}{*}{ Female } & 1 st & $6.17 \pm 0.94$ & $6.17 \pm 1.64$ & $6.18 \pm 1.11$ & $5.80 \pm 1.26$ \\
\hline & 2nd & $6.48 \pm 1.05$ & $5.92 \pm 1.41$ & $5.90 \pm 1.33$ & $5.44 \pm 1.15$ \\
\hline
\end{tabular}

Table 4. Average Pinch Strength of All Subjects Using a Different Dynamometer

\begin{tabular}{llccr}
\hline \multicolumn{1}{c}{ Dynamometer } & & Pinch strength $(\mathbf{k g})$ & t value & p-value \\
\hline Preston Pinch Gauge & & $8.53 \pm 1.9$ & & 0.608 \\
Digitalized Pinch Dynamometer & Rater 1 & $8.48 \pm 1.9$ & 0.515 & $<0.001$ \\
& Rater 2 & $8.09 \pm 2.0$ & 3.752 & 0.15 \\
\hline
\end{tabular}


Table 5. Intraclass Correlation Coefficients of Pinch Strengths between Preston Pinch Gauge and Digitalized Pinch Dynamometer (Inter-instrumental Reliability)

\begin{tabular}{|c|c|c|}
\hline & \multicolumn{2}{|c|}{ ICC } \\
\hline & Rater 1 & Rater 2 \\
\hline Pinch strength & $0.82(0.75-0.87)^{*}$ & $0.78(0.70-0.84)^{*}$ \\
\hline
\end{tabular}

Table 6. Intraclass Correlation Coefficients of Pinch Strengths between First Session and Second Session (Intra-rater Reliability)

\begin{tabular}{lcc}
\hline & Rater 1 & Rater 2 \\
\hline $\begin{array}{l}\text { Digitalized Pinch } \\
\text { Dynamometer }\end{array}$ & $0.87(0.79-0.92)^{*}$ & $0.88(0.81-0.93)^{*}$ \\
${ }^{*} \mathrm{p}<0.001$ & & \\
\hline
\end{tabular}

relation coefficients were statistically significant (Table 6) $(\mathrm{p}<0.001)$.

Comparison between rater 1 and rater 2 of Digitalized Pinch Dynamometer

The correlation coefficient between the pinch strength values measured by rater 1 and rater 2 was 0.75 . This value was statistically significant (Table 7$)(\mathrm{p}<0.001)$.

\section{DISCUSSION}

The development of digitalized dynamometers began about 20 years ago. In contrast to existing analogue gauges, digitalized dynamometers have the merits of improved inter-instrumental reliability due to the digital display, accurate and precise measurement, and convenient use owing to the electronic saving and retrieval of information. However, studies on the reliability and accuracy of many of these digitalized dynamometers have rarely been done. ${ }^{16}$ Fess ${ }^{14}$ stressed the importance of examining reliability for a new assessment instrument before using it in the clinical setting.

Reliability can be described as a correlation coefficient (Pearson's correlation coefficient and ICC) and standard error. $^{11,14,15}$ The ICC value of 0.75 to 0.90 can be considered as having relatively high correlation. Therefore, the results of this study show that the Digitalized Pinch Dynamometer has good intra-rater and inter-rater reliability, and also has good reliability compared with the existing Preston Pinch Gauge. So it can be concluded that the Digitalized Pinch Dynamometer is a suitable instrument
Table 7. Intraclass Correlation Coefficients of Pinch Strengths between Rater 1 and Rater 2 (Inter-rater Reliability)

\begin{tabular}{lcc}
\hline & ICC & $\begin{array}{c}\mathbf{9 5 \%} \\
\text { confidence } \\
\text { interval }\end{array}$ \\
\hline Digitalized Pinch Dynamometer & $0.75^{*}$ & $0.66-0.82$ \\
\hline${ }^{*} \mathrm{p}<0.001$ & &
\end{tabular}

for measuring pinch muscle strength.

This study adopted the standard procedures of producing high reliability found during the course of many research studies ${ }^{4,6,8,9,11,12,15}$ on accurate measurement. There was a break of 10 minutes between the end of testing with one instrument and the start of testing with the next instrument in order to reduce errors due to muscle fatigue. The measurement procedure was designed on the basis of the following studies: Mathiowet ${ }^{15}$ set a break of 5 minutes to reduce participants' muscle fatigue in his study that compared the Rolyan dynamometer and Jamar dynamometer, Shechtman et al. ${ }^{11}$ set 10 minutes as a break time to compare the DynEx Dynamometer and Jamar dynamometer.

When it comes to comparing the mean values of pinch strength measured with the Preston Pinch Gauge and Digitalized Pinch Dynamometer, the result of the T-test showed that the measurements done by rater 1 were no different between the two instruments, but for rater 2 , the measurements using the Digitalized Pinch Dynamometer were significantly lower (average $0.4 \mathrm{~kg}$, p<0.05) than those using the Preston Pinch Gauge. The reason for this seems to be the normal error of individuals reported by Hinson et al. ${ }^{16}$ Another reason might be that the subjects were affected by muscle fatigue because all the tests of rater 2 were performed at the end of each test.

Niebuhr et al. ${ }^{12}$ examined grip strength of 33 normal people with the PC5030PT Computerized Jamar Dynamometer, measuring the slope of rise in the force, the peak force and the mean sustained force. In that study, it was suggested that in addition to the peak force, which is commonly used in the clinical setting, the slope of the rise in force and the mean sustained force are also clinically useful. Likewise, the Digitalized Pinch Dynamometer developed by our institute can measure real-time pinch strength, and from these values, a graph of changes in force can be obtained.

In addition to the advantages of existing digitalized dy- 
namometers, which include digital display, accurate and precise measurement, and ability to store information, the Digitalized Pinch Dynamometer can also determine the level of participation of the subjects at the time of the test through a graph of changes in force that is created during the measurement of pinch strength. In addition, as the recent study of Weinstock-Zlotnick et al. ${ }^{17}$ shows, the visual feedback to the subjects in the form of a graph displaying changes in force on the computer screen can increase their pinch strength. Therefore, the Digitalized Pinch Dynamometer can also be used as a visual feedback training tool for hand rehabilitation of stroke patients or patients with peripheral nerve injury.

\section{CONCLUSION}

The Digitalized Pinch Dynamometer showed high inter-rater and intra-rater reliability when measuring pinch strength, and higher inter-instrumental reliability compared to existing analogue instruments. The main advantage of the Digitalized Pinch Dynamometer lies in its digitalized nature-increased accuracy due to the digital display, ease of data processing, and precise measurement. Moreover, we can also use it to check the level of participation of the subjects and as a training tool using visual feedback of pinch strength.

Therefore, we conclude that the Digitalized Pinch Dynamometer is a useful clinical instrument for measuring pinch strength.

\section{REFERENCES}

1. Balogun JA, Akomolafe CT, Amusa LO. Grip strength: effects of testing posture and elbow position. Arch Phys Med Rehabil 1991; 72: 280-283

2. Myers DB, Grennan DM, Palmer DG. Hand grip function in patients with rheumatoid arthritis. Arch Phys Med Rehabil 1980; 61: 369-373

3. Han SH, Nam KS, Ahn TK, Dan JM. Analysis of grip and pinch strength in Korean people. J Korean Orthop Assoc 2009; 44: 219-225

4. Mathiowetz V, Kashman N, Volland G, Weber K, Dowe
M, Rogers S. Grip and pinch strength: normative data for adults. Arch Phys Med Rehabil 1985; 66: 69-74

5. Richards LG. Posture effects on grip strength. Arch Phys Med Rehabil 1997; 78: 1154-1156

6. Schmidt RT, Toews JV. Grip strength as measured by the Jamar dynamometer. Arch Phys Med Rehabil 1970; 51: 321-327

7. Bechtol CO. Grip test: the use of a dynamometer with adjustable handle spacings. J Bone Joint Surg Am 1954; 36: 820-824

8. Mathiowetz V, Weber K, Volland G, Kashman N. Reliability and validity of grip and pinch strength evaluations. J Hand Surg Am 1984; 9: 222-226

9. Mathiowetz V, Wiemer DM, Federman SM. Grip and pinch strength: norms for 6- to 19-year-olds. Am J Occup Ther 1986; 40: 705-711

10. Talsania JS, Kozin SH. Normal digital contribution to grip strength assessed by a computerized digital dynamometer. J Hand Surg Br 1998; 23: 162-166

11. Shechtman O, Gestewitz L, Kimble C. Reliability and validity of the DynEx dynamometer. J Hand Ther 2005; 18: $339-347$

12. Niebuhr BR, Marion R, Fike ML. Reliability of grip strength assessment with the computerized Jamar dynamometer. Occup Ther J Res 1994; 14: 3-18

13. Kim HM, Yoon JW, Shin HS, Kim GS. Development of force measuring system using three-axis force sensor for measuring two-finger force. J Inst Contr Robot Syst 2010; 16: 876-882

14. Fess EE. The need for reliability and validity in hand assessment instruments. J Hand Surg Am 1986; 11: 621-623

15. Mathiowetz V. Comparison of Rolyan and Jamar dynamometers for measuring grip strength. Occup Ther Int 2002; 9: 201-209

16. Hinson M, Woodard J, Gench B. Reliability of the Jamar digital dynamometer model 2A. Occup Ther J Res 1990;10:108-110

17. Weinstock-Zlotnick G, Bear-Lehman J, Yu TY. A test case: does the availability of visual feedback impact grip strength scores when using a digital dynamometer? J Hand Ther 2011; 24: 266-275 